\title{
171. Paper Chromatographic Detection of N-Acylaminosugars in Human Semen
}

\author{
By Seiichi Ohkuma and Chitose Miyauchi \\ Biochemical Laboratory, Scientific Police Research Institute*1 \\ (Comm. by T. Furuhata, M.J.A., Dec. 12, 1962)
}

In 1945-6, $\operatorname{Man}^{1)}$ reported the presence of fructose in bull semen. Identification was effected by the preparation of p-methylphenylosazone of fructose. Goto and Ugami ${ }^{2}$ used later a different technique, paper chromatography, and found to contain only fructose in bull semen. Kubíček and Šantavý ${ }^{13)}$ reported that fructose is accompanied with glucose, xylulose, ribose, ribulose and some polysaccharides in the seminal fluids of men and several other animals. Clemont, Glegg and Leblond ${ }^{4)}$ reported that the acrosome of guinea pig spermatozoon contains galactose, mannose, fucose and hexosamines. However, the presence of $\mathrm{N}$-acylaminosugars in free form in human semen has not yet been clarified.

Paper chromatography appears to be a sensitive method for the detection of the free $\mathrm{N}$-acylaminosugars in human semen, and it has been applied for that purpose. Preliminary chromatograms on semens from men failed to reveal the presence of the free $\mathrm{N}$-acylaminosugars. However, when the semens were deionized, concentrated and chromatographed, then several $\mathrm{N}$-acylaminosugars appeared. The present paper describes the methods employed for deionization, paper chromatography, and identification of the free $\mathrm{N}$-acylaminosugars in human semen.

Experimental. Deionization and concentration. From 3 to $5 \mathrm{ml}$ of fresh semen from man was dialysed in a cellophan bag against 300$500 \mathrm{ml}$ of distilled water at $4-5^{\circ} \mathrm{C}$ for 24 hours. After dialysis, the dialysate was passed through a column (12mm in internal diameter and $150 \mathrm{~mm}$ long) of Amberlite IR-120 resin (hydrogen form), 100200 mesh, and the column was washed with $30-50 \mathrm{ml}$ of distilled water. The effluent and washings are combined. The combined solution was then passed through a column $(12 \mathrm{~mm}$ in internal diameter and 150 $\mathrm{mm}$ long) of Amberlite IR-4B resin (hydroxyl form), 100-200 mesh, and the column was washed with $30-50 \mathrm{ml}$ of distilled water. The rate of flow of the effluents was $1 \mathrm{ml} /$ minute. The effluent and washings are combined. The combined solution was concentrated to about $2-3 \mathrm{ml}$ at $45-50^{\circ} \mathrm{C}$ under vacuum and the concentrated solution was

*1. Sanban-cho, Chiyoda-ku, Tokyo. 
evaporated to dryness in a vacuum desiccator. The residue was taken up in $0.12-0.2 \mathrm{ml}$ of distilled water, and about $0.0025-0.0050 \mathrm{ml}$ of the resulting solution (sample solution) was applied to the origin of the paper strip.

Paper chromatography. Paper chromatography of sample solution was performed by the following methods (method 1-method 3). One-dimensional paper chromatography was used. The identification of the N-acylaminosugars from sample solution was carried out by comparison with a known mixture of chemically pure $\mathrm{N}$-acetylhexosamines. The rate of movement of each sugar has been expressed $\mathrm{R}_{F}$ value or $\mathrm{R}_{G}$ value.

$$
\mathrm{R}_{G} \text { value }=\frac{\begin{array}{c}
\text { Movement of distance }(\mathrm{cm}) \text { of } \mathrm{N} \text {-acylaminosugar } \\
\text { (or N-acetylhexosamine) }
\end{array}}{\text { Movement of distance }(\mathrm{cm}) \text { of glucose }}
$$

Method 1.5) Paper chromatography was carried out on Whatman No. $3 \mathrm{MM}$ and Toyo No. $50(2 \times 40 \mathrm{~cm})$ papers impregnated with $0.1 \mathrm{M}$ sodium tetraborate by means of the method described in a previous paper, ${ }^{5)}$ in Solvent A (n-butanol-pyridine-water, $4: 6: 3$ by volume) and Solvent B (n-butanol-pyridine-water, 2:2:1 by volume) by the ascending technique. The $\mathrm{N}$-acylaminosugars and $\mathrm{N}$-Acetylhexosamines were detected as follows: the chromatograms were first sprayed with watersaturated n-butanol, heated at $105^{\circ} \mathrm{C}$ for 5 minutes and then sprayed with the $\mathrm{DMBA}^{* 2}$ spray reagent. ${ }^{6}$ )

Method 2.7 Paper chromatography was carried out on Whatman No. 1 paper $(2 \times 40 \mathrm{~cm})$, in Solvent C (n-butanol-pyridine-water, 6:4:3 by volume), Solvent $\mathrm{D}$ (water-saturated phenol) and Solvent $\mathrm{E}(\mathrm{n}$ butanol-acetic acid-water, $4: 1: 5$ by volume), by the descending technique. The $\mathrm{N}$-acylaminosugars and $\mathrm{N}$-acetylhexosamines on chromatograms were detected as follows: the chromatograms were first sprayed with an ethanol-borate mixture ${ }^{8)}$ and heated at $105^{\circ} \mathrm{C}$ for 5 minutes, and then sprayed with DMBA spray reagent. ${ }^{6}$ )

Method 3.9) Paper chromatography was carried out on Whatman No. 1 paper $(2 \times 40 \mathrm{~cm})$ impregnated with $0.1 \mathrm{M}$ barium chloride, in Solvent $\mathrm{C}$ by the descending technique. The $\mathrm{N}$-acylaminosugars and $\mathrm{N}$-acetylhexosamines on chromatograms were detected as follows: the chromatograms were first sprayed with an ethanol-borate-sodium hydroxide mixture (this spray reagent is made up by mixing $25 \mathrm{ml}$ of ethanol-borate mixture ${ }^{8)}$ and $0.25 \mathrm{ml}$ of $0.2 \mathrm{~N}$ sodium hydroxide) and heated at $105^{\circ} \mathrm{C}$ for 10 minutes, and then sprayed with the DMBA spray reagent. ${ }^{6)}$

Results. The $\mathrm{R}_{F}$ values and $\mathrm{R}_{G}$ values of the $\mathrm{N}$-acylaminosugars

*2. The abbreviations used are: M-E, Morgan-Elson; DMBA, p-Dimethylaminobenzaldehyde; GleNAc, N-Acetylglucosamine; GalNAc, N-Acetylgalactosamine; ManNAc, $\mathrm{N}$-Acetylmannosamine. 
from sample solution and of three authentic $\mathrm{N}$-acetylhexosamines are summarized in Table I-Table IV. It will be convenient to refer to the $\mathrm{N}$-acylaminosugars as Spots $1,2,3, \cdots$, in order of increasing $R_{I^{\prime}}$ values or $\mathrm{R}_{G}$ values.

Method 1. On chromatograms developed in Solvent A and Solvent $B$, the modified $M-E$ reagents revealed six violet spots (in Solvent A) and seven violet spots (in Solvent B).

(1) Paper chromatography using Solvent A. Spot 1, Spot 2, and Spot 3 were identified as GalNAc, ManNAc, and GlcNAc, respectively, by their color reactions with the modified M-E reagents and by their $\mathrm{R}_{F}$ values (Tables I and II). Spot 4, Spot 5, and Spot 6 are unknown N-acylaminosugars. Spot 1 and Spot 3 reacted intensely on chromatograms with the modified M-E reagents, whereas Spot 2 and Spot 4 gave relatively weak reactions. The order of color intensities of these violet spots is shown as follows; Spot $3>$ Spot $1>$ Spot $2>$ Spot 4. Spot 5 and Spot 6 were much weaker than Spot 4 and could easily be missed with small quantities of sample solution.

(2) Paper chromatography using Solvent B. Spot 1, Spot 2, and Spot 3 were identified as GalNAc, ManNAc, and GlcNAc, respectively, by their color reactions with the modified M-E reagents and by their $\mathrm{R}_{F}$ values (Tables I and II). Spot 4, Spot 5, Spot 6, and Spot 7 are unknown N-acylaminosugars. Spot 1 and Spot 3 reacted intensely on chromatograms with the modified M-E reagents, whereas Spot 2 and Spot 4 gave relatively weak reaction.

The order of color intensities of these violet spots is shown as follows; Spot $3>$ Spot $1>$ Spot $2>$ Spot 4. Spot 5, Spot 6, and Spot 7 were much weaker than Spot 4, and could easily be missed with small quantities of sample solution.

Table I. Paper chromatography of authentic N-acetylhexosamines

\begin{tabular}{|c|c|c|c|c|c|c|c|c|c|}
\hline \multicolumn{4}{|c|}{ Condition of developement } & \multicolumn{6}{|c|}{$\mathrm{R}_{F}$ value of $\mathrm{N}$-acetylhexosamine } \\
\hline \multirow{2}{*}{$\begin{array}{l}\text { Sol- } \\
\text { vent }\end{array}$} & \multirow{2}{*}{ Paper*3 } & \multirow{2}{*}{$\underset{\left({ }^{\circ} \mathrm{C}\right)}{\text { Temp. }}$} & \multirow{2}{*}{$\underset{(\mathrm{hr})}{\mathrm{Time}}$} & \multicolumn{3}{|c|}{ For single } & \multicolumn{2}{|c|}{ For mixture } & \multirow[b]{2}{*}{ GleNAc } \\
\hline & & & & GalNAc & ManNAc & GlcNAc & GalNAc & ManNAc & \\
\hline \multirow{2}{*}{$\mathrm{A}$} & $\begin{array}{l}\text { Whatman } \\
\text { No. 3MM }\end{array}$ & $10 \rightarrow 7$ & 16 & 0.20 & 0.29 & 0.43 & 0.20 & 0.29 & 0.45 \\
\hline & $\begin{array}{l}\text { Toyo } \\
\text { No. } 50\end{array}$ & $10 \rightarrow 6$ & 18 & 0.20 & 0.31 & 0.44 & 0.22 & 0.32 & 0.46 \\
\hline \multirow{2}{*}{ B } & $\begin{array}{l}\text { Whatman } \\
\text { No. 3MM }\end{array}$ & $9 \rightarrow 7$ & 17 & 0.11 & 0.16 & 0.33 & 0.11 & 0.17 & 0.31 \\
\hline & $\begin{array}{l}\text { Toyo } \\
\text { No. } 50\end{array}$ & $9 \rightarrow 6$ & 18 & 0.12 & 0.17 & 0.34 & 0.11 & 0.16 & 0.34 \\
\hline
\end{tabular}

${ }^{* 3}$ : Paper impregnated with $0.1 \mathrm{M} \mathrm{Na}{ }_{2} \mathrm{~B}_{4} \mathrm{O}_{7}$. 
Table II. Paper chromatography of N-acylaminosugars from human semen

\begin{tabular}{c|c|c|c|c|c|c|c|c|c|c}
\hline \multicolumn{3}{c}{ Condition of developement } & \multicolumn{5}{c}{$\mathrm{R}_{F}$ value of N-acetylhexosamine } \\
\hline Solvent & Paper*3 & $\begin{array}{c}\text { Temp. } \\
\left({ }^{\circ} \mathrm{C}\right)\end{array}$ & $\begin{array}{c}\text { Time } \\
(\mathrm{hr})\end{array}$ & $\begin{array}{c}\text { Spot } \\
1\end{array}$ & $\begin{array}{c}\text { Spot } \\
2\end{array}$ & $\begin{array}{c}\text { Spot } \\
3\end{array}$ & $\begin{array}{c}\text { Spot } \\
4\end{array}$ & $\begin{array}{c}\text { Spot } \\
5\end{array}$ & $\begin{array}{c}\text { Spot } \\
6\end{array}$ & $\begin{array}{c}\text { Spot } \\
7\end{array}$ \\
\hline $\mathrm{A}$ & $\begin{array}{c}\text { Whatman } \\
\text { No. 3MM }\end{array}$ & $10 \rightarrow 7$ & 16 & 0.19 & 0.27 & 0.46 & 0.53 & 0.63 & 0.72 & - \\
\hline $\begin{array}{l}\text { Toyo } \\
\text { No. 50 }\end{array}$ & $10 \rightarrow 6$ & 18 & 0.21 & 0.29 & 0.46 & 0.54 & 0.66 & 0.71 & - \\
\hline $\begin{array}{l}\text { Whatman } \\
\text { No. 3MM }\end{array}$ & $9 \rightarrow 7$ & 17 & 0.12 & 0.16 & 0.30 & 0.43 & 0.46 & 0.56 & 0.66 \\
\hline $\begin{array}{l}\text { Toyo } \\
\text { No. 50 }\end{array}$ & $9 \rightarrow 6$ & 18 & 0.12 & 0.17 & 0.34 & 0.42 & 0.47 & 0.59 & 0.68 \\
\hline
\end{tabular}

${ }^{* 3}$ : Paper impregnated with $0.1 \mathrm{M} \mathrm{Na} \mathrm{Ba}_{4} \mathrm{O}_{7}$.

Table III. Paper chromatography of authentic N-acetylhexosamines

\begin{tabular}{|c|c|c|c|c|c|c|c|c|c|}
\hline \multicolumn{4}{|c|}{ Condition of developement } & \multicolumn{6}{|c|}{$\mathbf{R}_{G}$ value of $\mathrm{N}$-acetylhexosamine } \\
\hline \multirow{2}{*}{ Method } & \multirow{2}{*}{ Solvent } & \multirow{2}{*}{$\underset{\left({ }^{\circ} \mathrm{C}\right)}{\text { Temp. }}$} & \multirow{2}{*}{$\begin{array}{c}\text { Time } \\
(\mathrm{hr})\end{array}$} & \multicolumn{3}{|c|}{ For single } & \multicolumn{3}{|c|}{ For mixture } \\
\hline & & & & GalNAc & ManNAc & GleNAc & GalNAc & ManNAc & GlcNAc \\
\hline \multirow{3}{*}{2} & C & $10 \rightarrow 6.5$ & 21 & 1.18 & 1.30 & 1.30 & 1.11 & 1.23 & 1.23 \\
\hline & $\mathrm{D}$ & $11 \rightarrow 8$ & 24 & 2.04 & 1.94 & 1.88 & 1.92 & 1.92 & 1.92 \\
\hline & $\mathrm{E}$ & $11 \rightarrow 7$ & 21 & 1.68 & 2.18 & 1.95 & 2.02 & 2.02 & 2.02 \\
\hline 3 & $\mathrm{C}$ & $7 \rightarrow 6$ & 21 & 1.10 & 1.44 & 1.28 & 1.10 & 1.46 & 1.10 \\
\hline
\end{tabular}

Table IV. Paper chromatography of N-acylaminosugars from human semen

\begin{tabular}{c|c|c|c|c|c|c}
\hline \multicolumn{3}{c|}{ Condition of developement } & \multicolumn{2}{c}{$\mathrm{R}_{G}$ value of N-acetylaminosugar } \\
Method & Solvent & $\begin{array}{c}\text { Temp. } \\
\left({ }^{\circ} \mathrm{C}\right)\end{array}$ & Time & Spot 1 & Spot 2 & Spot 3 \\
\hline 2 & $\mathrm{C}$ & $10 \rightarrow 6.5$ & 21 & 1.19 & 1.27 & 1.72 \\
\hline \multirow{2}{*}{2} & $\mathrm{D}$ & $11 \rightarrow 8$ & 24 & 1.90 & 2.35 & - \\
\hline 3 & $\mathrm{E}$ & $11 \rightarrow 7$ & 21 & 1.94 & 5.57 & 6.27 \\
\hline
\end{tabular}

Method 2. On chromatogram developed in Solvent C, the modified M-E reagents revealed three violet spots (Tables III and IV). Of these, Spot 1 and Spot 2 could not be completely separated from each other. Spot 1 had the same mobility as GalNAc. Spot 2 had the same mobility as GlcNAc or ManNAc, which are not distinguishable under this condition. Spot 3 is an unknown $\mathrm{N}$-acylaminosugar. On chromatogram developed in Solvent D, the modified M-E 
reagents revealed two violet spots (Tables III and IV). Spot 1 (the major spot) showed a $R_{G}$ value of GlcNAc, GalNAc or ManNAc, which are not separated from one another under this condition. Spot 2 (the second spot) is an unidentified $\mathrm{N}$-acylaminosugar. On chromatogram developed in Solvent E, the modified M-E reagents revealed three violet spots (Tables III and IV). Spot 1 (the major spot) had the same mobility as GlcNAc, GalNAc or ManNAc, which are not separated from one another under this condition. Spot 2 and Spot 3 were much weaker than Spot 1 and could easily be missed with small quantities of sample solution.

Method 3. On chromatogram, the modified M-E reagents revealed three violet spots (Tables III and IV). Spot 2 and spot 3 reacted intensely on chromatograms with the modified M-E reagents, whereas Spot 1 gave relatively weak reaction. Spot 1 and Spot 2 could not be completely separated under this condition. Spot 1 had the same mobility as GalNAc or GlcNAc, which are not distinguishable in this condition.

Discussion. The free $\mathrm{N}$-acylaminosugars in human semen are present in small quantities that, in order to obtain satisfactory chromatograms, it is necessary to remove not only inorganic salts but also weakly ionized organic compounds such as amino acids, peptides, biogenic amines, organic acids and phosphates. For the elimination of the seminal substances except neutral compounds and the concentration of the free $\mathrm{N}$-acylaminosugars in human semen, the use of ion-exchange resins has been found to be useful.

It is evident from the experimental results obtained by means of the method 2 and method 3 that it is impossible to identify the free $\mathrm{N}$-acylaminosugars in human semen by these methods. However, these data suggest that the majority of the free $\mathrm{N}$-acylaminosugars in human semen are $\mathrm{N}$-acetylhexosamine such as GlcNAc, GalNAc or ManNAc. Under the chromatographic conditions of the method 1, the free $\mathrm{N}$-acylaminosugars from human semen were separated from six to seven components which give a positive reaction with the modified M-E reagents. The $\mathrm{R}_{F}$ values and the color intensities of the violet spots separated indicate that the major $\mathrm{N}$-acylaminosugar is GlcNAc and the second GalNAc, and then the third is probably ManNAc.

From these results presented above, it is therefore concluded that GlcNAc, GalNAc, ManNAc and some unidentified N-acylaminosugars occur in free form in human semen, and that ascending chromatography $^{5)}$ on paper impregnated with $0.1 \mathrm{M}$ sodium tetraborate, using n-butanol-pyridine-water (2:2:1 or $4: 6: 3$ by volume) solvent system is useful for the identification of the $\mathrm{N}$-acylaminosugars in human 
semen. Rigorous identification of these $\mathrm{N}$-acetylhexosamines in human semen is still, however, possible only after these pure sugars have been isolated.

Acknowledgments. The authors wish to thank Professor T. Furuhata, the Director of Scientific Police Research Institute, for his guidance and encouragement. The authors also wish to thank Dr. H. Kushida, of Research Laboratory, Kakenyaku Ka-ko Co. Ltd., for a gift of $\mathrm{N}$-acetylmannosamine, and Dr. M. Watanabe and Dr. S. Watanabe, of Scientific Police Research Institute, for their support and interest.

Summary. A method has been developed, involving the use of ion-exchange resins for the preparation of human semen concentrate suitable for the paper chromatographic detection of small amounts of $\mathrm{N}$-acylaminosugars. The semens of normal adults were examined and the following free $\mathrm{N}$-acylaminosugars are detected: $\mathrm{N}$-acetylglucosamine, $\mathrm{N}$-acetylgalactosamine, $\mathrm{N}$-acetylmannosamine and some $\mathrm{N}$ acylaminosugars which give a positive reaction with the Morgan-Elson reagents.

\section{References}

1) T. Mann: Biochem. J., 399, 458 (1945), 40, xxix, 481 (1946); Nature, 157, 79 (1946).

2) T. Goto and S. Ugami: Bull. Natl. Inst. Agr. Sci. (Japan) Ser. G., No. 3, 123 (1952).

3) R. Kubíček and F. Šantavý: Č́asopis lékařơ českých., 96, 1549 (1957); Chem. Abst., 52, 13951 (1958).

4) Y. Clemont, R. E. Glegg, and C. P. Leblond: Exptl. Cell Research., 8, 453 (1955); Chem. Abst., 50, 3586 (1956).

5) S. Ohkuma: Proc. Japan Acad., 38, 562 (1962).

6) S. M. Partridge: Biochem. J., 42, 238 (1948).

7) M. J. Crumpton: Biochem. J., 72, 479 (1959).

8) M. R. J. Salton: Biochim. Biophys. Acta., 34, 308 (1959).

9) R. Heyworth, H. R. Perkins and P. G. Walker: Nature., 190, 261 (1961). 